\title{
Transfer Patterns and Drivers of Embodied Agricultural Land within China: Based on Multi-Regional Decomposition Analysis
}

\author{
Mengyao Han ${ }^{1,2,3, *(D)}$ and Shuchang $\mathrm{Li}^{1,4}$ \\ 1 Institute of Geographic Sciences and Natural Resources Research, Chinese Academy of Sciences, \\ Beijing 100101, China; 1012172113@cugb.edu.cn \\ 2 Key Laboratory of Regional Sustainable Development Modeling, Chinese Academy of Sciences, \\ Beijing 100101, China \\ 3 College of Resources and Environment, University of Chinese Academy of Sciences, Beijing 100049, China \\ 4 School of Land Science and Technology, China University of Geosciences, Beijing 100083, China \\ * Correspondence: hanmy@igsnrr.ac.cn; Tel.: +86-10-6488-9817
}

check for updates

Citation: Han, M.; Li, S. Transfer Patterns and Drivers of Embodied Agricultural Land within China: Based on Multi-Regional Decomposition Analysis. Land 2021 10, 213. https://doi.org/10.3390/ land 10020213

Academic Editor: Elisa Marraccini

Received: 31 December 2020

Accepted: 17 February 2021

Published: 20 February 2021

Publisher's Note: MDPI stays neutral with regard to jurisdictional claims in published maps and institutional affiliations.

Copyright: (c) 2021 by the authors. Licensee MDPI, Basel, Switzerland. This article is an open access article distributed under the terms and conditions of the Creative Commons Attribution (CC BY) license (https:// creativecommons.org/licenses/by/ $4.0 /)$.

\begin{abstract}
Agricultural land is fundamental to human survival and economic development. Unlike other resources, land resources are embodied in trade goods and commodities, which are continuously re-allocated between countries and regions. As a typical ecological element, agricultural land embodied in trade activities can play an essential role in allocating land resources and advancing agricultural development. Based on the multi-regional decomposition analysis, this study investigated the embodied agricultural land flows among 31 provinces/municipalities of China, and classified the transfer patterns into different drivers including intensity-, trade-, and specialization-driven types. The results showed that the total amount of embodied agricultural land is approximately half of the direct agricultural land use area. Among these regions, Heilongjiang had the largest embodied agricultural land outflows, while Guangdong showed a deficit of agricultural land with embodied inflows. For regions such as Heilongiiang, the relatively high intensity and trade specialization significantly contributed to the embodied agricultural land outflows. For municipalities such as Beijing and Shanghai in China, the embodied agricultural land played a practical role in balancing increasingly scarce land resources. From the embodied perspective, agricultural land linkages between supply and demand in different regions could provide a new perspective to address the agricultural land shortage and avoid the inefficient transfer flows, contributing to the optimal allocation of agricultural land within China.
\end{abstract}

Keywords: agricultural land; input-output analysis; transfer pattern; decomposition analysis; driving factor

\section{Introduction}

Agricultural land is fundamental to human survival and economic development [1]. However, rapid urbanization and economic expansion has led to a scarcity in agricultural land resources, especially in population-intensive countries such as China [2]. To prevent the agricultural land shortage, the requisition-compensation balance of arable land was proposed in the 1990s as a supplemental strategy to guarantee the quantities and qualities of arable land [3,4]. As an important component of the economy, the reasonable distribution of agricultural land resources can help to optimize resource utilization efficiency [5]. Unlike other resources, land could not be freely distributed as other factors. When associated with trade activities, however, agricultural land resource flows can be transferred through goods and services to achieve multi-regional reallocation [6,7]. Particularly, indirect land use changes due to bioenergy activities also draw due attention [8].

The concept of embodied land was derived from the concept of embodied energy [9], which refers to the sum of land resources directly and indirectly used to produce a product 
or service $[10,11]$. All produced goods and services are supported either directly or indirectly by land resources, and thus it is practical to consider the role of land use resources embodied in goods and services [12]. Even though land cannot be physically transferred or freely allocated, these resources can be re-allocated between different countries and regions through trade activities. Similarly to other embodied resources and environmental elements, the research on embodied land has increasingly drawn attention $[13,14]$.

Given the potential to connect resource consumption and economic development, most studies have applied input-output analysis (IOA) to analyze the industrial connections within a country, region, or city. Since economies and regions have become more closely linked, multi-regional input-output analysis (MRIO) was applied to assess the linkage between production and consumption in different economies [15-17]. Based on this method, research has been conducted in the areas of energy consumption $[18,19]$, greenhouse gas emissions [20,21], water consumption [22,23], and land use [24,25]. On the basis of relations between food, water and land, existing studies also focused on the food-water-land and water-energy-land nexus [26,27]. Moreover, some studies further linked the regional and global datasets to analyze the emission trade balance embodied in interregional and international trade $[21,28]$. Given the complexity of regional associations and the possibility of data availability, the MRIO analysis has been gradually applied to address issues remaining in the field of resource consumption and environment emissions.

Specific to land resources, existing research mainly focused on the allocation and utilization of direct land resources. With the increasing conflicts between economic development, resource consumption, and environment emissions, more attention has been paid to the connections between general resource scarcity and regional economic development [29-31]. From the perspective of embodied land, the supply and demand of different types of land use within China and outside of China were analyzed [10,32]. The arable land use of the world economy from source to sink has been explored via the global supply chains [33]. Based on the multi-regional input-output analysis, the global undernourishment and agricultural land displacement were also investigated between countries and regions [34]. In consideration of the agricultural trade, the land use embodied in the United Kingdom and Switzerland were quantified $[35,36]$. These studies provided a solid foundation for land use assessments within economic systems; however, the drivers and patterns of the embodied agricultural land flows have not received enough attention.

Although relevant studies are limited, some researchers also investigated land transfer drivers. Among them, Taherzadeh and Caro [14] assessed the water and land use embodied in international soybean trade and analyzed the drivers based on physical trade analysis. Infante-Amate et al. [37] applied a decomposition analysis to analyze the drivers of land embodied in trade and consumption in Spain, and mentioned that land demand increased accompanied with increased dietary consumption. Weinzettel et al. [38] applied a multivariate regression analysis to assess the drivers of global land use embodied in trade, identifying that export production caused significant pressure on land use in less populous countries.

China has less than one-third of the world's land area per capita, and less than one-half of the world's average agricultural land per capita [39]. To alleviate the agricultural land scarcity, a series of policies have been introduced, including land finance systems and requisition-compensation balance $[40,41]$. However, the potential to improve the efficiency of direct agricultural land utilization is gradually dropping. As such, more attention could be paid to the agricultural land transfer system embodied in trade mechanisms. The studies mentioned above have scientifically analyzed the relations between land use and economic development in different regions. The ecological values and biodiversity were also hotspots during multi-regional land use exchanges [42,43]. However, few studies investigated the patterns and drivers of embodied land flows within China, especially taking the inefficient and imbalanced flows into consideration. By exploring the patterns and drivers of embodied land flows, it is critical to identify the positive flows and avoid the 
negative flows, qualify the impact of different driving factors, and optimize land resource allocation system.

Based on the input-output modelling and decomposition analysis, this study takes 31 provinces/municipalities into consideration to explore the utilization and allocation of embodied agricultural land between China's provinces and regions. In this regard, the transfers, patterns, and drivers of the trade-related agricultural land flows within China are depicted, especially focusing on the inefficient and imbalanced flows. By assessing land use intensity, transfer structures, and driving factors, it is practical to assess the transfer patterns between different regions and identify the main factors for agricultural land transfer optimization, which is expected to relieve land use pressure and achieve regional coordinated development. The remainder of the study proceeds as follows: Section 2 describes the method used in this study; Section 3 analyzes the detailed results; Section 4 discusses the policy implications; and Section 5 draws the conclusions.

\section{Materials and Methods}

\subsection{Multi-Regional Input-Output Analysis}

To identify and analyze the embodiment of resources in different economic activities, input-output tables have been widely employed to explore the economic interdependence of different economies and to assess the resource flows [16,17]. The model integrates economic networks and resource endowments by examining the physical balance of resource use for a regional system comprising $m$ regions, each involving $n$ sectors. In this study, the MRIO technique was developed to analyze embodied agricultural land flows between China's provinces and municipalities. The input-output structure is presented in Table 1.

The multi-regional input-output analysis could be used to depict the embodied resource and environmental flows between various regions [20,44]. The basic economic balance could be described as:

$$
x_{i}^{r}=\sum \sum z_{i, j}^{r, s}+d_{i}^{r, s}+e x_{i}^{r}+o_{i}^{r}=\sum \sum z_{i, j}^{r, s}+p_{i}^{r}
$$

where $x_{i}^{r}$ denotes the total output of sector $i$ in region $r, z_{i, j}^{r, s}$ denotes the intermediate use from sector $i$ in region $r$ to sector $j$ in region $s, d_{i}^{r, s}$ denotes the final demand of sector $i$ from region $r$ to region $s, e x_{i}^{r}$ represents the exports from sector $i$ in region $r, o_{i}^{r}$ denotes the balance items of sector $i$ in region $r$, and $p_{i}^{r}$ denotes the sum of the items.

The total land use balance can be obtained as:

$$
c_{i}^{r}+\varepsilon_{i}^{f} i m_{i}^{f}+\sum \sum \varepsilon_{j}^{s} z_{j, i}^{s, r}=\sum \sum \varepsilon_{i}^{r} z_{i, j}^{r, s}+\varepsilon_{i}^{r} p_{i}^{r}
$$

where $c_{i}^{r}$ is the direct land use of sector $i$ in region $r, \varepsilon_{i}^{f}$ is the average embodied intensity of sector $i$ from other regions, which is derived from the previous studies [11], $i m_{i}^{f}$ is the imported embodied land of sector $i$ in region $f$ from other regions, and $\varepsilon_{j}^{s}$ is the intensity of sector $j$ in region $s$. It is assumed that for different provinces/municipalities, the domestic and foreign embodied intensities are unequal. 
Table 1. Input-output structure.

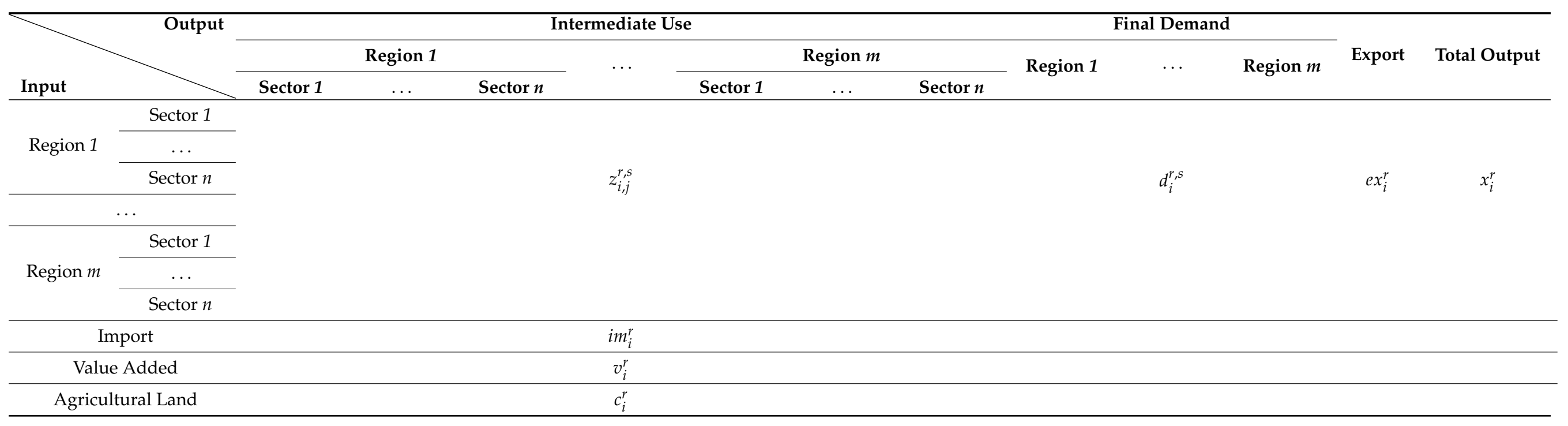


Direct land use $(C)$ denotes the direct land use within a certain region's territory:

$$
C_{r}=\sum c_{i}^{r}
$$

Embodied land use (CEU) denotes the land required for the region's final demand:

$$
C E U_{r}=\sum \sum \varepsilon_{i}^{s} d_{i}^{s, r}
$$

where $e_{i}^{r}$ denotes the direct land use of Sector $i$ in Region $r$, and $d_{i}^{s, r}$ denotes the final demand for sector $i$ from region $s$ to region $r$. The land use intensity means the total land use divided by gross domestic production, while per capita land use is defined as the total land use divided by the population.

For the embodied land flows in the commodity/service trade flows, embodied land inflows (CIM) and outflows (CEX) can be derived as:

$$
\begin{aligned}
& \text { CIM }_{r}=\sum \sum \varepsilon_{i}^{s} \times i m_{i}^{s, r} \\
& \text { CEX }_{r}=\sum \sum \varepsilon_{i}^{r} \times e x_{i}^{r, s}
\end{aligned}
$$

The net land use embodied in the interregional trade balance is defined as the gap between CIM and CEX.

\subsection{Multi-Regional Decomposition Analysis}

The decomposition method, represented by the Logarithmic Mean Divisia Index (LMDI) decomposition method, was generally used to quantify the relative influence of various factors on energy demand and the energy intensity of the industrial sector [45,46]. Later, it was gradually expanded to the analysis of various sub-sectors, including the decomposition of carbon emissions and water resources. Generally, the common factors that are dismantled mainly include GDP, structure, and intensity. Two commonly used methods are index decomposition analysis (IDA) and structural decomposition analysis (SDA), which could be further extended to the S/S method in IDA and the D\&L method in SDA.

The multi-regional decomposition analysis could be used to depict the drivers contributing to the embodied resource and environmental flows between various regions [47]. For region $r$ in China, resource embodied in domestic outflows can be written as:

$$
C E X_{r}=\left[\frac{C_{r}}{G D P_{r}}\right] \times \frac{\left[\frac{C E X_{r}}{E X_{r}}\right]}{\left[\frac{C_{r}}{G D P_{r}}\right]} \times E X_{r}=C I_{r} \times s p_{r} \times E X_{r}
$$

where $E X_{r}$ represents the domestic outflows of region $r$ in China, $C E X_{r}$ represents the resource use embodied in domestic outflows of region $r, G D P_{r}$ represents the gross domestic product of region $r, C_{r}$ represents the different kinds of resource use from the production of region $r, C I_{r}$ represents the land use intensity of region $r$, and $s p_{r}$ represents the land use intensity of region $r$, and $s p_{r}$ represents the specialization degree of domestic outflows of region $r$.

To carry out a decomposition of a given sub-region's embodied resource inflows and outflows, the net domestic outflows of an embodied resource of region $r$ are introduced as:

$$
C E X_{r}-C I M_{r}=C I_{r} \times s p_{r} \times E X_{r}-C I_{c \mid r} \times s p_{c \mid r} \times I M_{c \mid r}
$$

where $I M_{r}$ represents the domestic inflows of region $r, C I M_{r}$ represents the resource use embodied in domestic inflows of region $r$, and $c \mid r$ represents other regions except region $r$ in China. 
Denoted by the prefix $\Delta$, the difference in the respective factors between region $r$ in Equation (2) can be decomposed and expressed as a sum of three terms:

$$
\begin{gathered}
C E X_{r}-C I M_{r}= \\
T B_{r} \times\left[C I_{c \mid r} \times s p_{c \mid r}+\frac{1}{2}\left(\Delta C I_{r} \times s p_{c \mid r}+C I_{c \mid r} \times \Delta s p_{r}\right)+\frac{1}{3} \Delta s p_{r} \times \Delta C I_{r}\right] \\
+\Delta C I_{r} \times\left[I M_{r} \times s p_{c \mid r}+\frac{1}{2}\left(T B_{r} \times s p_{c \mid r}+I M_{r} \times \Delta s p_{r}\right)+\frac{1}{3} \Delta s p_{r} \times T B_{r}\right] \\
+\Delta s p_{r} \times\left[C I_{c \mid r} \times I M_{r}+\frac{1}{2}\left(\Delta C I_{r} \times I M_{r}+C I_{c \mid r} \times T B_{r}\right)+\frac{1}{3} T B_{r} \times \Delta C I_{r}\right]
\end{gathered}
$$

where $T B_{r}$ represents the trade balance (or net domestic outflows $E X_{r}-I M_{r}$ ) of region $r$. The driving factors associated with embodied flows can be attributed to trade-, intensity-, and specialization-driven factors.

\subsection{Data Sources}

Overall, China has a total cultivated land area of 133.39 million hectares (ha), which is scarce when taking the population into account $[39,48]$. Agricultural land resources are distributed unevenly, and significant gaps remain in the agricultural land intensity of different regions [49]. Specifically, Heilongjiang, Inner Mongolia, Henan, Hebei, and Shandong have a relatively large share in the national agricultural land area. In contrast, agricultural land in Shanghai, Beijing, and Tianjin is most scarce, making up less than 1\% of the total agricultural land area in China.

To analyze embodied flows of agricultural land, this study investigated agricultural land use, population, and economic conditions of 31 provinces/municipalities in China [50,51]. The multi-regional socio-economic data were collected from the China Statistical Yearbook and the key data in the second national land resource investigation bulletin [48], which contains the economic development and land use data of provinces / municipalities in China (in Table S1). The study adopted China's commonly used multiregional input-output tables, established by Liu et al. [52] to represent the multi-regional relations between provinces/municipalities in China. Using the latest compiled table for multi-regional input-output data in 2012, this study was able to depict the embodied agricultural land flows and analyze the patterns and drivers between different provinces / municipalities. Due to data limitations, 31 provinces/municipalities in China Mainland were assessed in this study, and the provinces and municipalities were grouped into seven major regions (as shown in Table 2). Detailed results are presented in the Supplementary Materials for reference.

Table 2. China's regional divisions.

\begin{tabular}{ccc}
\hline No. & Category & Province/Municipality \\
\hline 1 & North China & Beijing, Tianjin, Hebei, Shanxi, Inner Mongolia \\
2 & Northeast China & Liaoning, Jilin, Heilongjiang \\
3 & East China & Shanghai, Jiangsu, Zhejiang, Anhui, Fujian, Jiangxi, Shandong \\
4 & Central China & Henan, Hubei, Hunan \\
5 & South China & Guangdong, Guangxi, Hainan \\
6 & Southwest China & Chongqing, Sichuan, Guizhou, Yunnan, Tibet \\
7 & Northwest China & Shaanxi, Gansu, Qinghai, Ningxia, Xinjiang \\
\hline
\end{tabular}

\section{Results}

\subsection{Transfer Flows of Embodied Agricultural Land}

In general, China has a total cultivated land area of 133.39 million ha. Provinces such as Heilongjiang, Inner Mongolia, and Henan hold significant percentages of land areas in China, accounting for $11.95 \%, 6.89 \%$, and $6.14 \%$ of the total, respectively. Considering that agricultural land can be transferred through commodity trades, the embodied agricultural land flows could be assessed based on the supply and demand balance between provinces/municipalities. Among them, Heilongjiang, Inner Mongolia, Henan, 
Shandong, Anhui, and Gansu have experienced large agricultural land outflows to other provinces, mainly due to the huge areas of agricultural land and large amounts of trade volume. In contrast, some provinces such as Shandong, Guangdong, and Liaoning had large agricultural land deficits.

Table 3 presents the main embodied agricultural land flows between China's provinces and municipalities. Heilongiiang, Shandong, Anhui, Inner Mongolia, and Henan provided large amounts of gross agricultural land demand for other provinces and municipalities. In particular, Heilongjiang exported the equivalent of 1266.78, 1107.25, 737.08, 624.43, 556.10, 491.96, and 447.67 kha of embodied agricultural land to Shandong, Guangdong, Zhejiang, Jiangsu, Liaoning, Henan, and Inner Mongolia, respectively. The total amounts of embodied agricultural land flows nationwide are estimated as 64,469.42 ha, of which flows into Anhui, Inner Mongolia, and Henan all exceeded 1000 kha. Among them, Shandong was the main recipient of embodied agricultural land, with suppliers including Heilongjiang (1.96\% of the total), Anhui (0.77\%), Gansu (0.68\%), Xinjiang (0.64\%), Henan $(0.62 \%)$, and Inner Mongolia (0.59\%). The agricultural land flows embodied in China's multi-regional trade are further illustrated in Table S2.

Table 3. The main embodied agricultural land gross transfer flows (kha).

\begin{tabular}{|c|c|c|c|c|c|}
\hline No. & Flow Direction & Amount & No. & Flow Direction & Amount \\
\hline 1 & Heilongjiang $\rightarrow$ Shandong & 1266.78 & 11 & Inner Mongolia $\rightarrow$ Guangdong & 447.26 \\
\hline 2 & Heilongjiang $\rightarrow$ Guangdong & 1107.25 & 12 & Gansu $\rightarrow$ Shandong & 437.86 \\
\hline 3 & Heilongjiang $\rightarrow$ Zhejiang & 737.08 & 13 & Henan $\rightarrow$ Guangdong & 428.48 \\
\hline 4 & Heilongjiang $\rightarrow$ Jiangsu & 624.43 & 14 & Shandong $\rightarrow$ Jiangsu & 414.63 \\
\hline 5 & Heilongjiang $\rightarrow$ Liaoning & 556.10 & 15 & Xinjiang $\rightarrow$ Shandong & 409.74 \\
\hline 6 & Shandong $\rightarrow$ Guangdong & 519.37 & 16 & Henan $\rightarrow$ Shandong & 401.03 \\
\hline 7 & Anhui $\rightarrow$ Jiangsu & 502.50 & 17 & Anhui $\rightarrow$ Guangdong & 391.25 \\
\hline 8 & Anhui $\rightarrow$ Shandong & 496.50 & 18 & Inner Mongolia $\rightarrow$ Jiangsu & 389.49 \\
\hline 9 & Heilongjiang $\rightarrow$ Henan & 491.96 & 19 & Henan $\rightarrow$ Jiangsu & 382.39 \\
\hline 10 & Heilongjiang $\rightarrow$ Inner Mongolia & 447.67 & 20 & Inner Mongolia $\rightarrow$ Shandong & 381.69 \\
\hline
\end{tabular}

Figure 1 further depicts the trends in net agricultural land flows. Trade between provinces/municipalities has roughly formed a spatial transfer pattern of embodied agricultural land, generally from the Northwest, Northeast, and Central regions to the North, South, and East China regions. Overall, Heilongjiang, Inner Mongolia, Gansu, Jilin, Anhui, and Shaanxi were all in a state of agricultural land surpluses, with embodied agricultural land outflows to other provinces. Guangdong, Zhejiang, Shandong, Jiangsu, Shanghai, and Beijing showed deficits in agricultural land, with embodied agricultural land flowing in from other regions. In particular, the developed economies with high economic development levels, such as Beijing, Shanghai, Guangdong, Zhejiang, and Jiangsu, significantly benefited from the embodied agricultural land transfer system.

With the largest outflow, Heilongjiang played an essential role as a net supplier of agricultural land, in particular to Shandong, Guangdong, Zhejiang, Jiangsu, Liaoning, Shanghai, and Beijing. Inner Mongolia also exported more than 3000 ha of agricultural land to other provinces, including Guangdong, Jiangsu, Zhejiang, Shanxi, and Shandong. In contrast, Guangdong was the primary recipient of agricultural land, with the main suppliers including Inner Mongolia, Jilin, Heilongiiang, and Anhui. Zhejiang also received embodied agricultural land flows from Heilongjiang, Anhui, Inner Mongolia, Henan, and Shandong. 


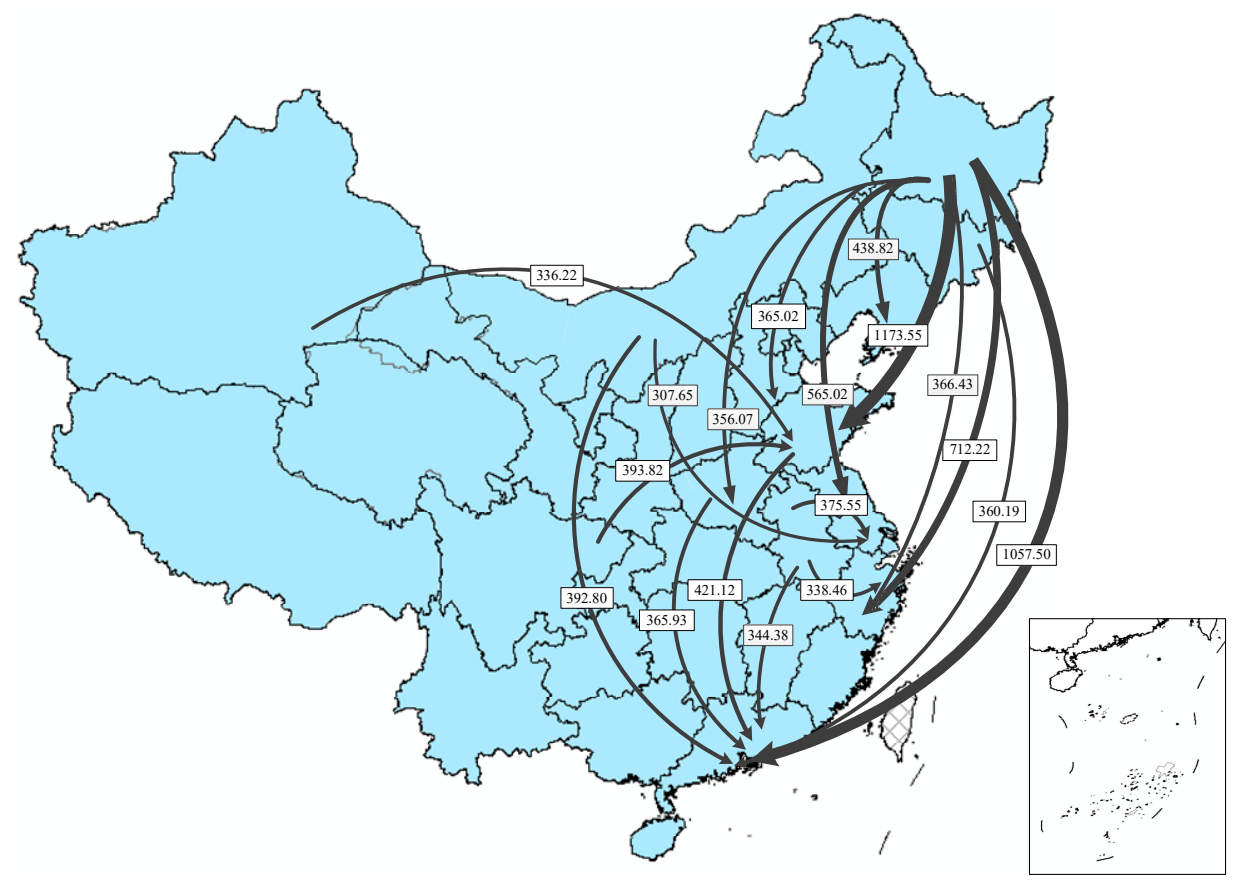

Figure 1. Net transfer flows of embodied agricultural land within China (unit: kha).

\subsection{Driving Factors of Embodied Agricultural Land Transfers}

For the driving factors associated with embodied agricultural land flows, the subregion's agricultural land transfers through domestic trade can be attributed to three distinct factors: (i) the trade balance (surplus or deficit); (ii) the agricultural land intensity; and (iii) the trade specialization. Overall, provinces with higher levels of agricultural land intensity included Heilongjiang, Inner Mongolia, Jilin, Anhui, Guangxi, Guizhou, Tibet, Yunnan, Gansu, and Xinjiang. In contrast, the agricultural land intensities were relatively low in Beijing, Tianjin, Shanghai, Zhejiang, Shandong, and Guangdong. As for the trade balance, Beijing, Tianjin, Liaoning, Jiangsu, and Shandong experienced a deficit, while Heilongjiang, Anhui, Jiangxi, Henan, Guangxi, Gansu, and Xinjiang experienced a surplus. Specific to trade specialization, there were relatively low specialization levels in Shanxi, Inner Mongolia, Jilin, Heilongjiang, Jiangsu, Anhui, and Gansu, while the specialization levels were relatively high in Beijing, Tianjin, Shandong, Shanghai, Zhejiang, Guangdong, and Tibet. The decomposition factor differences of China's provinces and municipalities are displayed in Table S3.

Table 4 further compares the differences between driving factors and net transfer flows. The intensity differences $(\triangle \mathrm{CI})$ in selected provinces, including Heilongjiang, Inner Mongolia, Jilin, Anhui, Guangxi, Guizhou, Tibet, Gansu, and Xinjiang, showed the same trend as the net embodied agricultural land flows. However, those trends were reversed in Shanxi, Hunan, Sichuan, Guizhou, Yunnan, Qinghai, and Tibet. For the trade balance $(\triangle \mathrm{TB})$, Hebei, Shanxi, Inner Mongolia, Jilin, Shanghai, Zhejiang, Guangdong, Chongqing, Sichuan, Qinghai, and Tibet showed the same trends as the net embodied agricultural land flows. In contrast, Beijing, Tianjin, Liaoning, Heilongjiang, Jiangsu, Anhui, Shandong, Henan, Guizhou, and Gansu experienced the opposite. In addition, the differences in trade specialization $(\triangle S P)$ in Beijing, Shandong, Shanghai, Zhejiang, Fujian, and Guangdong were similar to the net embodied agricultural land transfers. However, there was a reverse effect on the net embodied agricultural land flows in Shandong, Shanghai, and Guangdong. 
Table 4. Driving factors of the embodied agricultural land transfer flows.

\begin{tabular}{|c|c|c|c|c|c|c|c|c|c|c|c|}
\hline No. & Region & ETB & ТВ & $\triangle \mathbf{S P}$ & $\triangle \mathbf{C I}$ & No. & Region & ETB & ТВ & $\triangle \mathbf{S P}$ & $\triangle \mathrm{CI}$ \\
\hline 1 & Beijing & -2189.76 & 42.01 & 1.97 & -2.26 & 17 & Hubei & 169.92 & -38.14 & 0.19 & 0.08 \\
\hline 2 & Tianjin & -1063.19 & 237.43 & 0.52 & -2.02 & 18 & Hunan & 875.04 & 152.59 & 0.59 & -0.47 \\
\hline 3 & Hebei & 826.26 & 462.92 & -0.05 & 0.16 & 19 & Guangdong & -5355.61 & -83.52 & 0.07 & -2.06 \\
\hline 4 & Shanxi & -1149.73 & -107.74 & -0.74 & 1.07 & 20 & Guangxi & 971.52 & -98.20 & 0.35 & 1.11 \\
\hline 5 & Inner Mongolia & 2626.32 & 167.34 & -0.47 & 3.57 & 21 & Hainan & 154.76 & 8.78 & 0.12 & 0.24 \\
\hline 6 & Liaoning & -1086.28 & 142.65 & -0.30 & -0.70 & 22 & Chongqing & -807.40 & -178.62 & -0.25 & -0.18 \\
\hline 7 & Jilin & 2259.70 & 69.17 & 0.26 & 3.65 & 23 & Sichuan & -476.56 & -213.37 & -0.10 & 0.52 \\
\hline 8 & Heilongjiang & 7687.40 & -62.07 & 0.06 & 9.56 & 24 & Guizhou & 1076.94 & -141.79 & 0.15 & 4.40 \\
\hline 9 & Shanghai & -2423.26 & -131.16 & 2.27 & -2.30 & 25 & Yunnan & 423.80 & -391.88 & -0.11 & 3.81 \\
\hline 10 & Jiangsu & -2548.11 & 660.89 & 0.01 & -1.61 & 26 & Tibet & -25.77 & -69.43 & 5.63 & 4.01 \\
\hline 11 & Zhejiang & -3771.59 & -429.50 & 0.13 & -1.85 & 27 & Shanxi & 1264.93 & 104.40 & 0.40 & 0.46 \\
\hline 12 & Anhui & 1858.65 & -138.24 & 0.37 & 1.15 & 28 & Gansu & 2263.79 & -66.89 & 0.10 & 7.33 \\
\hline 13 & Fujian & -1079.38 & -15.94 & 0.55 & -1.69 & 29 & Qinghai & -30.95 & -70.61 & 0.30 & 0.80 \\
\hline 14 & Jiangxi & 141.40 & -95.22 & 0.29 & 0.07 & 30 & Ningxia & 26.30 & -81.23 & -0.09 & 2.41 \\
\hline 15 & Shandong & -2856.90 & 865.06 & -1.08 & -0.85 & 31 & Xinjiang & 1185.46 & -231.22 & 0.39 & 3.22 \\
\hline 16 & Henan & 1052.32 & -268.45 & 0.31 & 0.48 & & & & & & \\
\hline
\end{tabular}

Note: ETB represents the difference of land use embodied in interregional trade, $\Delta \mathrm{SP}$ represents the difference of $\mathrm{SP}_{\mathrm{r}}$ between region $r$ and the rest of China $c \mid r, \Delta \mathrm{CI}$ represents the difference of $\mathrm{CI}_{\mathrm{r}}$ between region $r$ and the rest of $\mathrm{China} c \mid r$.

Figure 2 further evaluates the contribution of different factors driving the embodied agricultural land transfers. Overall, agricultural land intensities significantly contribute to the embodied outflows from Heilongjiang, Inner Mongolia, Gansu, Yunnan, and Jilin, which were negative when compared with the direction of agricultural land flows. Generally, the higher the agricultural land intensities in the province, the larger the outflows of agricultural land out of the region. For most provinces, including Hebei, Inner Mongolia, Hunan, Shaanxi, and Jilin, the trade balance also had dominant effects on the outflows of embodied agricultural land. Closely related to the trade balance, the degree of the agricultural land specialization played an essential role in the agricultural land outflows. For regions such as Heilongjiang, Gansu, Jilin, Anhui, Xinjiang, Guizhou, Henan, and Shaanxi, the trade specialization factor significantly contributed to the agricultural land outflows.

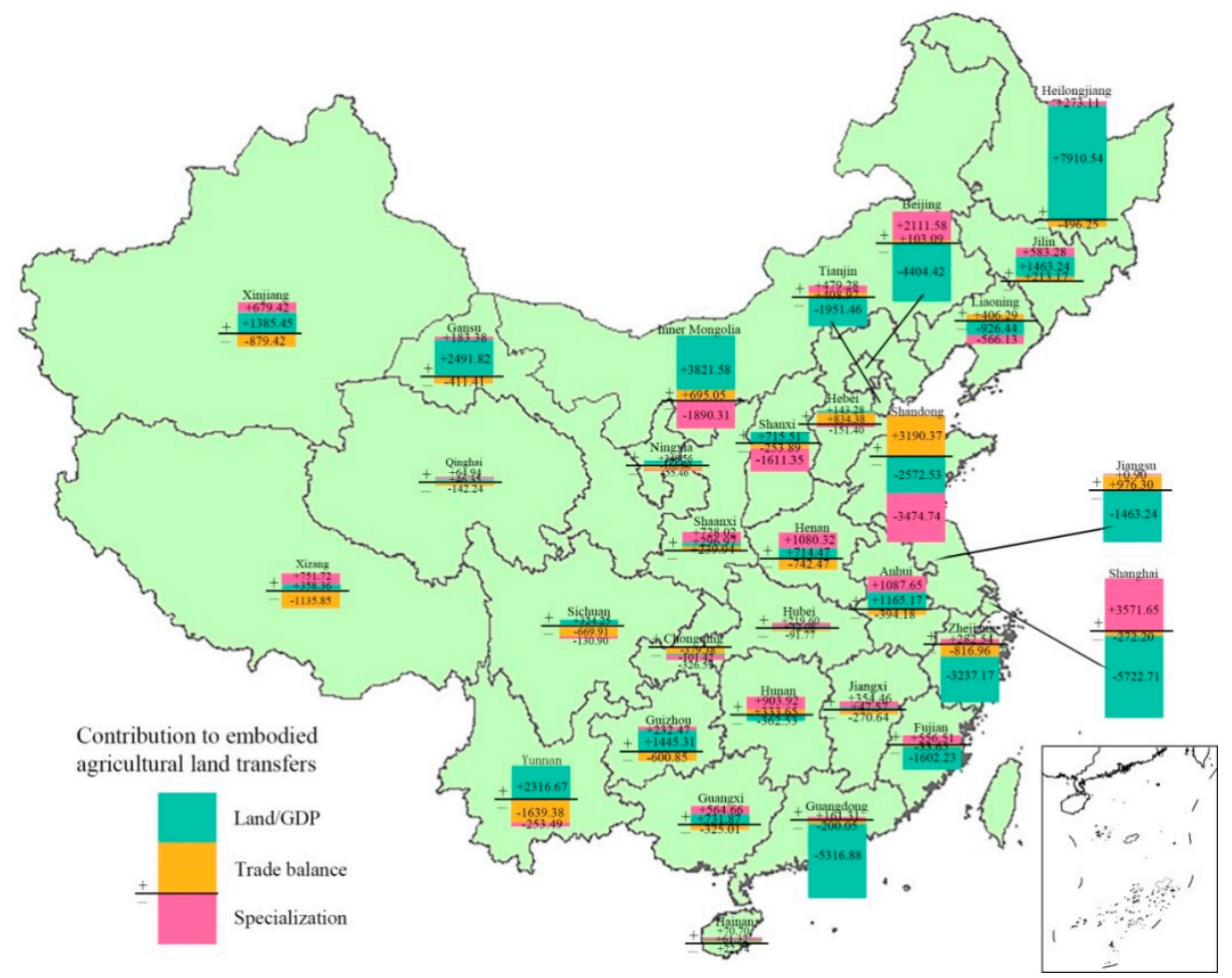

Figure 2. Embodied agricultural land transfer drivers. Note: The bar above the line represents the net outflow of embodied agricultural land, and that below the line represents the net inflow. 
Unlike outflows, inflows are also affected by corresponding factors, particularly for regions with scarce land resources. Several regions with a relatively small area of agricultural land, including Beijing, Zhejiang, Shanghai, and Guangdong, still needed large amounts of embodied agricultural land from other provinces and regions. For economies such as Shanghai, Guangdong, Beijing, Jiangsu, and Zhejiang, the lower agricultural land intensities significantly contributed to the embodied inflows from other regions. As for the deficits in Guangdong, Shanxi, Tibet, Zhejiang, Sichuan, Chongqing, and Shanghai, the trade balance contributed to the embodied agricultural land inflows. In addition, the relatively high trade specialization also significantly contributed to those inflows, especially in Shandong, Shanxi, Liaoning, Chongqing, and Sichuan. Details are also outlined in Table S4.

\subsection{Transfer Patterns of the Agricultural Land Flows}

Agricultural land plays an essential role in the sustainable economic development of land-scarce regions. As China's economy has rapidly developed, the utilization of agricultural land exposed several issues. Due to rapid urbanization and industrialization in China, the transfer flows of agricultural land resources embodied in the goods and services have become increasingly more essential. In this process, the embodied flows of agricultural land within China can play a significant role in optimizing the interregional agricultural land flows and achieving coordinated regional development.

In general, the total amount of embodied agricultural land through commodity flows has reached $48.33 \%$ of the total direct agricultural land use in China. Guangdong, Zhejiang, and Shandong were all in the state of agricultural land inflows, which represents the fact that embodied agricultural land was flowing in from other provinces. In contrast, Heilongjiang, Inner Mongolia, and Jilin are provinces with embodied agricultural land outflows, satisfying the agricultural land demands in other provinces/municipalities. For large municipalities such as Beijing and Shanghai, the embodied inflows of agricultural land significantly contributed to the balance between the supply and demand of landintensive products, making it possible to mitigate their agricultural land pressures.

Overall, the supply and demand of embodied agricultural land in most provinces/ municipalities are positively correlated with their agricultural land endowments. Table 5 compares the agricultural land endowments with the transfer relations. Here, the endowment levels are measured by the per capita agricultural land area; the larger the per capita agricultural land area, the higher the endowment. Most provinces/municipalities with high endowments of agricultural land were in a state of outflows. However, there was still an imbalance between the endowment of agricultural land resources and the supply and demand relations in some provinces/municipalities. Provincesmunicipalities such as Hebei, Anhui, Henan, Hubei, Hunan, Guangxi, Hainan, and Jiangxi served as agricultural land suppliers, but were in states of agricultural land shortages. The adjustments of embodied agricultural land flows between provinces/municipalities can thus maximize the resource advantages for those with higher agricultural land endowments and relieve the pressure of agricultural land shortages in areas with high demands. 
Table 5. Agricultural land balances between land endowments and transfer relations.

\begin{tabular}{|c|c|c|}
\hline Balance Endowment & Regions with Net Outflows & Regions with Net Inflows \\
\hline High Endowment ${ }^{a}$ & $\begin{array}{l}\text { Heilongjiang, Inner Mongolia, Jilin, Guizhou, } \\
\text { Yunnan, Shaanxi, Gansu, Ningxia, Xinjiang }\end{array}$ & Shanxi, Tibet, Qinghai \\
\hline Low Endowment ${ }^{\text {a }}$ & $\begin{array}{l}\text { Hebei, Anhui, Jiangxi, Henan, Hubei, Hunan, } \\
\text { Guangxi, Hainan }\end{array}$ & $\begin{array}{l}\text { Beijing, Tianjin, Liaoning, Shanghai, Jiangsu, } \\
\text { Zhejiang, Fujian, Shandong, Guangdong, } \\
\text { Chongqing, Sichuan }\end{array}$ \\
\hline \multicolumn{3}{|c|}{$\begin{array}{l}\text { a The endowment level is defined by the comparison between the per capita agricultural land area of each province and the national } \\
\text { average. The larger the per capita agricultural land area, the higher the endowment. }\end{array}$} \\
\hline & \multicolumn{2}{|c|}{$\begin{array}{l}\text { The agricultural land intensities of China's provinces/municipalities are compared } \\
\text { with the transfer relations in Table 6. When compared, China's agricultural land trans- } \\
\text { fer system was influenced by the land use intensities among provinces/municipalities, } \\
\text { Heilongjiang, Inner Mongolia, Jilin, Hebei, Anhui, Henan, Guangxi, Shaanxi, Guizhou, } \\
\text { Gansu, and Xinjiang were the main supply areas, with embodied agricultural land out- } \\
\text { flows and high agricultural land intensities. Meanwhile, some provinces, such as Guang- } \\
\text { dong, Shanghai, Beijing, Tianjin, Liaoning, Jiangsu, Zhejiang, Fujian, Shandong, and } \\
\text { Chongqing had relatively high agricultural land intensities, resulting in inefficient agri- } \\
\text { cultural land transfer inflows. To optimize the overall transfer intensity, it is practical for } \\
\text { these regions to lower agricultural land intensities and optimize inefficient flows between } \\
\text { provinces/municipalities. }\end{array}$} \\
\hline
\end{tabular}

Table 6. Agricultural land balance between land use intensity and supply-demand relations.

\begin{tabular}{ccc}
\hline Balance Endowment & Regions with Net Outflows & Regions with Net Inflows \\
\hline Low Intensity ${ }^{\text {a }}$ & Hunan & Beijing, Tianjin, Liaoning, Shanghai, Jiangsu, \\
& & Zhejiang, Fujian, Shandong, Guangdong, \\
Chongqing
\end{tabular}

Hebei, Inner Mongolia, Jilin, Heilongjiang, Anhui,

High Intensity a Jiangxi, Henan, Hubei, Guangxi, Hainan, Guizhou, Yunnan, Shaanxi, Gansu, Ningxia, Xinjiang
Shanxi, Sichuan, Tibet, Qinghai

\footnotetext{
a The intensity level is defined by comparisons between the agricultural land area per economic output of each province and the national average.
}

Specific to transfer drivers behind the embodied agricultural land flows, three factors are dominant, including the agricultural land intensity, the trade balance, and the trade specialization (as presented in Table 7). With the largest agricultural land outflows, Heilongjiang had a relatively high agricultural land intensity and relatively high trade specialization level. As for Beijing and Shanghai, the commodity trade balance significantly contributed to the inflows of agricultural land. For provinces such as Heilongjiang, Inner Mongolia, and Gansu, the agricultural land intensities were much lower than the national average, which could be further reduced to release the agricultural land intensity.

Table 7. Driving categories of the embodied agricultural land transfer flows.

\begin{tabular}{ccc}
\hline Drivers & Regions with Outflows & Regions with Inflows \\
Intensity-driven & $\begin{array}{c}\text { Inner Mongolia, Jilin, Heilongjiang, Anhui, } \\
\text { Guangxi, Guizhou, Yunnan, Gansu, Ningxia, } \\
\text { Xinjiang }\end{array}$ & $\begin{array}{c}\text { Beijing, Tianjin, Liaoning, Shanghai, Jiangsu, } \\
\text { Zhejiang, Fujian, Guangdong }\end{array}$ \\
\hline Trade-driven & Hebei & Chongqing, Sichuan, Tibet, Qinghai \\
\hline Specialization-driven & Jiangxi, Henan, Hubei, Hunan, Hainan, Shaanxi & Shanxi, Shandong \\
\hline
\end{tabular}




\section{Discussion}

Spatial distance between countries and regions is no longer a barrier to resource exchanges along with the economic globalization. The movement of factors has kept production and consumption free from regional constraints, providing more possibilities for coordinated regional development and rational resource allocation. The red line of 120 million ha of agricultural land set in the 11th Five-Year Plan has significant implications for China Mainland, and the agricultural land scarcity could be further eased through the agricultural land flows associated with trade activities between countries and regions. By identifying the patterns and drivers of agricultural land transfers within China, this study could help to promote the balance between supply and demand of agricultural land in land-scarcity areas and coordinate sustainable development through the embodied agricultural land flows accurately. Four main points are discussed as follows.

(1) The embodied agricultural land flows have the potential to facilitate regional coordinated development and optimize embodied agricultural land flows between provinces/ municipalities. Overall, the total embodied agricultural land, along with the trade of commodities, reached $48.33 \%$ of the total agricultural land area in China. Specific to different regions, provinces such as Guangdong, Zhejiang, and Shandong with relatively low agricultural land per capita received embodied land inflows from other regions. In contrast, Heilongjiang, Inner Mongolia, and Gansu experienced significant outflows of embodied agricultural land to meet the demands of other provinces/municipalities. When compared, there were more agricultural land resources in North China compared to the South, and the uneven distribution and specialization among provinces/municipalities are the main factors driving embodied land transfers in China. With the possibility of accurately improving the agricultural land utilization efficiency, the embodied agricultural land flows accompanied by trade activities have the significant potential to facilitate regional coordinated development and mitigate agricultural land pressure.

(2) Embodied agricultural land flows contribute to the mitigation of shortages in agricultural land in China's metropolises. Beijing and Shanghai, for example, have serious scarcities of land resources, but relatively high demands for land-intensive products. The gap between direct use and final demand reflects a significant dependence on surrounding regions from the municipalities. With advanced urbanization and intensive populations, the conflicts between the protection of agricultural land and the growth of urbanization have gradually intensified. Even though the gaps in Tianjin and Chongqing were relatively small when compared to those in Shanghai and Beijing, these metropolises still need landintensive products to support their demands. The regional land resource utilization could be further optimized due to the supply-demand mechanism with embodied agricultural land flows. It would provide the potential for metropolises to address land resource constraints and optimize land resources utilization.

(3) Embodied agricultural land remains subject to inefficient and imbalanced dynamics in some provinces/municipalities in China. Embodied agricultural land has the potential to facilitate regionally coordinated development and to optimize agricultural land transfers. However, inefficient and imbalanced land use remains an issue. Specifically, some provinces, such as Hebei, Anhui, Jiangxi, Henan, and Hubei, have insufficient land areas, but still export embodied agricultural land. Taking the land use intensity into consideration, the land use intensities of provinces such as Hebei, Inner Mongolia, Jilin, Heilongjiang, and Anhui were relatively high, but had large outflows of embodied agricultural land. Overall, provinces such as Henan, Guangxi, and Anhui still exported embodied agricultural land use, despite having less direct agricultural land area per capita.

(4) The transfer drivers of embodied agricultural land contributed differently in China's provinces/regions. The transfer drivers could be classified into intensity-driven, trade-driven, and specialization-driven types. However, the main driving factors for the flows between different regions varied due to the different agricultural land intensities and endowments. Overall, provinces with high agricultural land endowments but with high agricultural land intensities, and provinces with low endowments but low intensities, 
mainly tended to be intensity-driven. Provinces with low agricultural land endowments and high agricultural land intensities tended to be specialization-driven. Provinces with high endowments and low intensities in agricultural land tended to be trade-driven. Based on the identification of the main transfer drivers, it is important to advance positive relations and decrease inefficient flows to optimize the overall efficiency in agricultural land transfer systems.

Under the 120 million ha of agricultural land red line, this study applied input-output modeling and decomposition analysis to improve agricultural land allocation efficiency, which could mitigate agricultural land pressure in scarce regions and optimize regionally coordinated development in China. The existing land transfer system in China has been significantly improved to increase the efficiencies in the direct use of land resources. However, considering the increasingly scarce agricultural land resources, the patterns, and drivers of embodied land allocation need to be further addressed.

(1) Some provinces within the embodied agricultural land transfer system have large endowments but high intensities of agricultural land, and some provinces have relatively large agricultural land areas but high intensity. These include Heilongjiang, Inner Mongolia, Jilin, Guizhou, Yunnan, Shaanxi, Gansu, Ningxia, and Xinjiang. Of these, many provinces are mainly intensity-driven, including Inner Mongolia, Jilin, Heilongjiang, Guizhou, Yunnan, Gansu, Ningxia, and Xinjiang. For this type of province, it is necessary to update agricultural technologies and lower land use intensities, which could maximize the overall efficiency of the agricultural land transfer system.

(2) Some provinces within the embodied agricultural land transfer system have low endowments and high intensities of agricultural land. These include Anhui, Hubei, Jiangxi, Henan, Guangxi, and Hainan. Of these, Hubei, Jiangxi, Henan, and Hainan are primarily specialization-driven. Along with the trade of commodities, the land-intensive products should be further evaluated. For these regions, strategies such as agricultural technology updates and trade structure adjustments would help avoid inefficient and imbalanced outflows.

(3) Municipalities with scarce amounts of agricultural land mainly received large shares of embodied agricultural land from other provinces/regions. Specifically, inflows from Heilongjiang, Inner Mongolia, Shandong, Henan, and Anhui contributed more than $45 \%$ to Beijing's total inflows, and inflows from Heilongjiang, Shandong, Anhui, Zhejiang, and Jiangsu contributed up to $40 \%$ to Shanghai's total inflows. These municipalities are generally intensity-driven, and should further diversify their agricultural land inflow sources and avoid embodied agricultural land inflows from land-scarcity areas.

(4) A few provinces, such as Hebei, Sichuan, Chongqing, and Liaoning, have relatively large agricultural land areas and relatively low intensities when compared with the national average. Of these, Hebei, Sichuan, and Chongqing are basically trade-driven. For these regions, improving the agricultural land efficiency and adopting advanced agricultural technologies could encourage the domestic transfers of agricultural land resources, mitigate agricultural land pressure, and balance land resource inequality among provinces.

This study mainly focused on China's multi-regional primary embodied agricultural land flows at the provincial level, which would be practical to further conduct a time-series investigation of evolution trends and link the regional and global datasets of embodied agricultural land flows. At present, there are few studies on embodied agricultural land, but the applications of the methods in this paper have been widely applied, which was reasonable and feasible to analyze the agricultural land embodied in interregional trade [25,30]. From the perspective of methodology, this study further identified the transfers, patterns, and drivers of the trade-related agricultural land flows within China, through combining inputoutput analysis and decomposition analysis, making a definite contribution to the existing research. Note that, there are still uncertainties and variabilities in this study. Factors such as the choice of input-output table, the sectoral aggregation, and the newest available data can facilitate the robustness of results. The findings of this study are expected to explore the differences in agricultural land among regional counterparts in China's domestic sub- 
regions, which could contribute to solving the problem of unbalanced agricultural land between different provinces, and finally realizing the rational and balanced allocation of agricultural land nationwide.

\section{Conclusions}

As the economy and society have developed and technology innovations have evolved, agricultural land has been redistributed as a type of product through trading mechanisms. To explore the multi-provincial embodied agricultural land transfer system in China, this study assessed the transfer patterns and drivers and identified inefficient and imbalanced transfer flows by comparing endowments and intensities from the embodied perspective. Overall, the total amount of embodied agricultural land transferred through the flow of China's commodities represents approximately half of the direct agricultural land use area, indicating a great potential in balancing the overall agricultural land pressure in China. There were 14 provinces/regions in China in a state of embodied agricultural land deficit, while provinces such as Guangdong, Zhejiang, and Shandong had large amounts of embodied agricultural land outflows. Meanwhile, municipalities such as Beijing and Shanghai received embodied agricultural land resources from other regions and significantly mitigated the pressure of agricultural land resources. Regarding the factors driving the embodied agricultural land transfers, the relatively high agricultural land intensities in regions such as Heilongjiang, Inner Mongolia, and Gansu contributed significantly to the outflows of embodied agricultural land use, which should be significantly reduced to a large scale. For provinces such as Shandong, the commodity trade balance contributed significantly to agricultural land outflows.

China has introduced diversified measures for the overall management of agricultural land utilization to increase land use efficiency and lower the pressure on agricultural land use. By analyzing embodied agricultural land flows within China, the country could further mitigate the conflict between supply and demand and optimize the efficiency of land resources based on the patterns and drivers of embodied agricultural land transfers. Different types of provinces/municipalities could adopt appropriate measures to improve agricultural land use efficiency, not only with respect to direct utilization but also through the transfer mechanisms. From the embodied perspective, agricultural land linkages between supply and demand in different regions can provide a new perspective to address the shortage of land resources and increase the utilization efficiency, contributing to the optimal allocation of agricultural land from a macro scale.

Supplementary Materials: The following are available online at https://www.mdpi.com/2073-4 45X/10/2/213/s1, Table S1: Socio-economic data of China's provinces/municipalities; Table S2: Agricultural land flows embodied in China's multi-regional trade; Table S3: Decomposition factor differences of China's provinces/municipalities; Table S4: Embodied agricultural land transfer contributions among China's provinces/municipalities.

Author Contributions: Conceptualization, M.H.; methodology, M.H. and S.L.; software, S.L.; data curation, S.L.; writing-original draft preparation, M.H. and S.L.; writing—review and editing, M.H.; visualization, S.L.; supervision, M.H. Both authors have read and agreed to the published version of the manuscript.

Funding: This work was funded by the National Key Research and Development Program of China (grant no. 2016YFA0602804) and the National Natural Science Foundation of China (grant no. 41701135).

Conflicts of Interest: The authors declare no conflict of interest.

\section{References}

1. Borgstrom, G. The hungry planet: The modern world at the edge of famine. J. Eur. Econ. Hist. 1965, $22,99-112$.

2. Liu, Y.S. Introduction to land use and rural sustainability in China. Land Use Policy 2018, 74, 1-4. [CrossRef]

3. Ministry of Land and Resources of the People's Republic of China. General Planning Outline of National Land Use (2006-2020). 2008. Available online: http:/ /www.gov.cn/zxft/ft149/content_1144625.htm (accessed on 19 February 2021). 
4. General Office of the State Council of the People's Republic of China. Outline of National Land Planning (2016-2030). 2017. Available online: http://www.gov.cn/zhengce/content/2017-02/04/content_5165309.htm (accessed on 19 February 2021).

5. Chen, J.; Wu, F.L. Housing and land financialization under the state ownership of land in China. Land Use Policy 2020, 104844. [CrossRef]

6. Kastner, T.; Rivas, M.J.I.; Koch, W.; Nonhebel, S. Global changes in diets and the consequences for land requirements for food. Proc. Natl. Acad. Sci. USA 2021, 109, 6868-6872. [CrossRef] [PubMed]

7. Yu, Y.; Feng, K.S. Tele-connecting local consumption to global land use. Glob. Environ. Chang. 2013, 23, 1178-1186. [CrossRef]

8. Bird, D.N.; Zanchi, G.; Pena, N. A method for estimating the indirect land use change from bioenergy activities based on the supply and demand of agricultural-based energy. Biomass Bioenergy 2013, 59, 3-15. [CrossRef]

9. Costanza, R. Embodied energy and economic valuation. Science 1980, 210, 1219-1224. [CrossRef]

10. Chen, G.Q.; Han, M.Y. Virtual land use change in China 2002-2010: Internal transition and trade imbalance. Land Use Policy 2015, 47, 55-65. [CrossRef]

11. Han, M.Y.; Chen, G.Q. Global arable land transfers embodied in Mainland China's foreign trade. Land Use Policy 2018, 70, 521-534. [CrossRef]

12. Kastner, T.; Schaffartzik, A.; Eisenmenger, N.; Erb, K.H.; Haberl, H.; Krausmann, F. Cropland area embodied in international trade: Contradictory results from different approaches. Ecol. Econ. 2014, 104, 140-144. [CrossRef]

13. Wilting, H.C.; Vringer, K. Carbon and land use accounting from a producer's and a consumer's perspective-An empirical examination covering the world. Econ. Syst. Res. 2009, 21, 291-310. [CrossRef]

14. Taherzadeh, O.; Caro, D. Drivers of water and land use embodied in international soybean trade. J. Clean. Prod. 2019, 223, 83-93. [CrossRef]

15. Lenzen, M.; Kanemoto, K.; Moran, D.; Geschke, A. Mapping the structure of the world economy. Environ. Sci. Technol. 2012, 46, 8374-8381. [CrossRef]

16. Wiedmann, T.; Lenzen, M.; Turner, K.; Barrett, J. Examining the global environment impact of regional consumption activitiesPart 2: Review of input-output models for the assessment of environment impacts embodied in trade. Ecol. Econ. 2007, 61, 15-26. [CrossRef]

17. Peters, G.P. From production-based to consumption-based national emission inventories. Ecol. Econ. 2008, 65, 13-23. [CrossRef]

18. Wu, X.F.; Chen, G.Q. Coal use embodied in globalized world economy: From source to sink through supply chain. Renew. Sustain. Energy Rev. 2018, 81, 978-993. [CrossRef]

19. Zhang, B.; Qiao, H.; Chen, Z.M.; Chen, B. Growth in embodied energy transfers via China's domestic trade: Evidence from multi-regional input-output analysis. Appl. Energy. 2016, 184, 1093-1105. [CrossRef]

20. Li, Y.L.; Chen, B.; Han, M.Y.; Dunford, M.; Liu, W.D.; Li, Z. Tracking carbon transfers embodied in Chinese municipalities' domestic and foreign trade. J. Clean. Prod. 2018, 192, 950-990. [CrossRef]

21. Han, M.Y.; Lao, J.M.; Yao, Q.H.; Tang, Z.P.; Liu, W.D. China's intra- and inter-national carbon emission transfers by province: A nested network perspective. Sci. China Earth Sci. 2020, 63, 852-864. [CrossRef]

22. Wu, X.D.; Guo, J.L.; Li, C.H.; Shao, L.; Han, M.Y.; Chen, G.Q. Global socio-hydrology: An overview of virtual water use by the world economy from source of exploitation to sink of final consumption. J. Hydrol. 2019, 573, 794-810. [CrossRef]

23. Lenzen, M.; Moran, D.; Bhaduri, A.; Kanemoto, K.; Bekchanov, M.; Geschke, A.; Foran, B. International trade of scarce water. Ecol. Econ. 2013, 94, 78-85. [CrossRef]

24. Han, M.Y.; Chen, G.Q.; Dunford, M. Land use balance for urban economy: A multi-scale and multi-type perspective. Land Use Policy 2019, 83, 323-333. [CrossRef]

25. Ji, X.; Han, M.Y.; Ulgiati, S. Optimal allocation of direct and embodied arable land associated to urban economy: Understanding the options deriving from economic globalization. Land Use Policy 2020, 91, 104392. [CrossRef]

26. Ali, T.; Huang, J.K.; Wang, J.X.; Xie, W. Global footprints of water and land resources through China's food trade. Glob. Food Secur. 2017, 12, 139-145. [CrossRef]

27. Oliver, T.; Mike, B.; Keith, R. Water, energy and land insecurity in global supply chains. Glob. Environ. Chang. 2020, 102158. [CrossRef]

28. Su, B.; Ang, B.W. Input-output analysis of $\mathrm{CO}_{2}$ emissions embodied in trade: A multi-region model for China. Appl. Energy 2014, 114, 377-384. [CrossRef]

29. Guo, S.; Shen, G.Q. Multiregional input-output model for China's farm land and water use. Environ. Sci. Technol. 2015, 49, 403-414. [CrossRef] [PubMed]

30. Guo, S.; Shen, G.; Chen, Z.; Yu, R. Embodied cultivated land use in China 1987-2007. Ecol. Indic. 2014, 47, 198-209. [CrossRef]

31. Rulli, M.C.; Saviori, A.; D’Odorico, P. Global land and water grabbing. Proc. Natl. Acad. Sci. USA 2012, 110, 892-897. [CrossRef]

32. Chen, G.Q.; Han, M.Y. Global supply chain of arable land use: Production-based and consumption-based trade imbalance. Land Use Policy 2015, 49, 118-130. [CrossRef]

33. Wu, X.D.; Guo, J.L.; Han, M.Y.; Chen, G.Q. An overview of arable land use for the world economy: From source to sink via the global supply chain. Land Use Policy 2018, 76, 201-214. [CrossRef]

34. Marselis, S.M.; Feng, K.S.; Liu, Y.; Teodoro, J.D.; Hubacek, K. Agricultural land displacement and undernourishment. J. Clean. Prod. 2017, 161, 619-628. [CrossRef] 
35. Wurtenberger, L.; Koellner, T.; Binder, C.R. Virtual land use and agricultural trade: Estimating environmental and socio-economic impacts. Ecol. Econ. 2006, 57, 679-697. [CrossRef]

36. de Ruiter, H.; Macdiarmid, J.I.; Matthews, R.B.; Kastner, T.; Lynd, L.R.; Smith, P. Total global agricultural land footprint associated with UK food supply 1986-2011. Glob. Environ. Chang. 2017, 43, 72-81. [CrossRef]

37. Infante-Amate, J.; Aguilera, E.; Palmeri, F.; Guzmán, G.; Soto, D.; García-Ruiz, R.; de Molina, M.G. Land embodied in Spain's biomass trade and consumption (1900-2008): Historical changes, drivers and impacts. Land Use Policy 2018, 78, 493-502. [CrossRef]

38. Weinzettel, J.; Hertwich, E.G.; Peters, G.P.; Steen-Olsen, K.; Galli, A. Affluence drives the global displacement of land use. Glob. Environ. Chang. 2013, 23, 433-438. [CrossRef]

39. FAO. FAOSTAT. Food and Agriculture Organization of the United Nations. 2012. Available online: http://www.fao.org/faostat/ en/\#data (accessed on 19 February 2021).

40. Fei, R.L.; Lin, Z.Y.; Chunga, J. How land transfer affects agricultural land use effciency: Evidence from China's agricultural sector. Land Use Policy 2021, 103, 105300. [CrossRef]

41. Gao, W.W.; de Vries, W.T.; Zhao, Q.Y. Understanding rural resettlement paths under the increasing versus decreasing balance land use policy in China. Land Use Policy 2021, 103, 105325. [CrossRef]

42. Dorninger, C.; Hornborg, A.; Abson, D.J.; von Wehrden, H.; Schaffartzik, A.; Giljum, S.; Engler, J.O.; Feller, R.L.; Hubacek, K.; Wieland, H. Global patterns of ecologically unequal exchange: Implications for sustainability in the 21st century. Ecol. Econ. 2021, 179, 106824. [CrossRef]

43. Chaudhary, A.; Kastner, T. Land use biodiversity impacts embodied in international food trade. Glob. Environ. Chang. 2016, 38, 195-204. [CrossRef]

44. Li, Y.L.; Han, M.Y. Embodied water demands, transfers and imbalance of China's mega-cities. J. Clean. Prod. 2018, 172, 1336-1345. [CrossRef]

45. Su, B.; Ang, B.W. Multiplicative structural decomposition analysis of aggregate embodied energy and emission intensities. Energy Econ. 2017, 65, 137-147. [CrossRef]

46. Li, J.S.; Wei, W.D.; Zhen, W.; Guo, Y.; Chen, B. How green transition of energy system impacts China's mercury emissions. Earth's Future 2019, 7, 1407-1416. [CrossRef]

47. Jakob, M.; Marschinski, R. Interpreting trade-related $\mathrm{CO}_{2}$ emission transfers. Nat. Clim. Chang. 2012, 3, 19-23. [CrossRef]

48. Ministry of Land and Resources. Bulletin of the Key Data on the Second National Land Resource Investigation. Available online: http:/ /www.gov.cn/jrzg/2013-12/31/content_2557453.htm (accessed on 19 February 2021).

49. Ye, S.J.; Song, C.Q.; Shen, S.; Gao, P.C.; Cheng, C.X.; Cheng, F.; Wan, C.J.; Zhu, D.H. Spatial pattern of arable land-use intensity in China. Land Use Policy 2020, 99, 104845. [CrossRef]

50. National Bureau of Statistics. China Statistical Yearbook 2012; China Statistics Press: Beijing, China, 2013.

51. National Bureau of Statistics. China Statistical Yearbook 2014; China Statistics Press: Beijing, China, 2015.

52. Liu, W.D.; Tang, Z.P.; Han, M.Y. The 2012 China Multi-Regional Input-Output Table of 31 Provincial Units; China Statistics Press: Beijing, China, 2018. 